\title{
Why Do Trade Negotiations Take So Long?
}

\author{
Christoph Moser and Andrew K. Rose*
}

Draft: 10 January 2012

\begin{abstract}
The Doha multilateral round of trade negotiations sponsored by the WTO has been dragging on for over a decade, with no end in sight. In this short paper we assess empirically what determines the duration of trade negotiations, focusing on the span between the start of trade talks and their conclusion. We use data from 88 regional trade agreements between 1988 and 2009, and a semi-parametric Cox proportional hazards model. Four factors are robust determinants of the length of RTA negotiations. Negotiations are more protracted when there are more countries at the negotiation table, and when the countries are not from the same region. Negotiations between more open and richer countries are also finished more quickly.
\end{abstract}

Keywords: regional; GATT; WTO; duration; income, data, empirical, Cox, survival

JEL codes: F13; F51; F53

Contact: Andrew K. Rose

Haas School of Business

University of California

Berkeley, CA USA 94720-1900

Tel: (510) 642-6609

Fax: (510) 642-4700

E-mail: arose@haas.berkeley.edu

URL: http://faculty.haas.berkeley.edu/arose

For Oesterreichische Nationalbank, CEEI Conference (November 2011) "European Integration in a Global Economic Setting - CESEE, China and Russia”

* The authors are respectively: post-doctoral researcher at ETH Zurich, KOF Swiss Economic Institute; and B.T. Rocca Jr. Professor of International Trade, NBER research associate and CEPR research fellow. We thank Christoph Trebesch for his guidance. 


\section{Introduction}

There is widespread agreement among economists that trade liberalization is best conducted at the multilateral level. Indeed, facilitating multilateral negotiations is one of the primary objectives of the World Trade Organization (WTO), as it was with its predecessor the General Agreement on Tariffs and Trade (GATT). By way of contrast, regional trade agreements (RTAs) may create some trade, but they also have the potential to harmfully divert it.

Still, the global approach to multilateral trade liberalization seems moribund. The Doha round sponsored by the WTO has just "celebrated" its tenth birthday, with no end in sight. Table 1 shows that the duration of GATT/WTO trade liberalization rounds - the length of time between the start of negotiations and their completion has grown consistently with the number of participants. The 23 participants of the first (Geneva) round of GATT negotiations took only six months to conclude a deal that reduced 45,000 tariffs. But there are now over 150 members of the WTO, a number that makes negotiations considerably more difficult. Moreover, membership in the WTO has continued to grow since the completion of the last (Uruguay) round, notably with the accession of countries like China (in late 2001) and, soon, Russia.

It may be problematic to generalize from the small number of observations on the duration of global (GATT/WTO) rounds of trade talks. Still, we have a large number of observations on regional trade negotiations. Since those are likely to be similar in nature to their GATT/WTO analogues, in this short paper, we study the determinants of the duration of RTA negotiations. We are motivated by the question: what effect does the complexity of trade negotiations have on the duration of those negotiations? We proxy complexity with two measures: a) the number of countries 
participating in the negotiation; and b) the regional diversity of those countries. We find that negotiations do indeed take significantly longer when they involve more countries, especially if the countries are spread across different regions. Thus it seems reasonable to us that one appeal of RTAs is the fact that they represent a feasible, if imperfect route, to greater trade integration. While all this is economically sensible, it still leaves us feeling depressed about the feasibility of the current Doha and future WTO rounds.

\section{Methodology and Data}

We estimate a standard Cox proportional hazards model that links the duration of RTA trade negotiations to a number of determinants (Cox, 1972); Cleves et al. (2004) provide a reference. This model assumes that the hazard takes the form:

$$
h(t)=h_{0}(t) \exp \left(\Sigma_{i} \beta_{i} x_{i}\right)
$$

where the baseline hazard is $h_{\circ}(t)$ is not directly estimated, $x$ 's are regressors, and the coefficients $\{\beta\}$ are estimated semi-parametrically. We estimate our models using the Efron method to handle ties, clustering our standard errors by RTA, and report our results in coefficients rather than in hazard ratios.

Our data sample includes 88 RTAs from 1988 to 2009; Moser and Rose (2011) provide more details. We consider all RTAs that have been signed and reported to the WTO. The universe of RTAs is drawn from the "Regional Trade 
Agreement Information System" (RTA-IS) database of the World Trade Organization (WTO), available at http://rtais.wto.org. ${ }^{1}$

A central component of our data set and identification strategy consists of a unique set of dates. We consider two important dates: a) the day when it was announced that negotiations on a RTA will commence at some future date (which we dub "Start"), and b) the day that agreement on the RTA was actually reached ("Deal"). ${ }^{2,3}$ The gap between these two dates constitutes the duration of the trade negotiation, used to construct our hazard rate. ${ }^{4}$ We identify the exact announcement dates through a full-text analysis on LexisNexis, where we mainly focus on international newswires, press releases and well-established newspapers published in English. ${ }^{5}$ Announcements of RTAs are usually made by prominent policy makers like the President, Prime Minister, or the minister of Finance, Economics, or Trade Minister of the country, and often precede official signature dates (as reported by the WTO) by several weeks or months. ${ }^{6}$ While RTA negotiations in our sample last on average for 28 months, Figure 1 displays considerable heterogeneity in their duration.

We link the duration of trade negotiations to a number of potential determinants (x's). Negotiations are likely to be more complicated as the number and regional diversity of members rises. Accordingly, we include as potential duration determinants both the natural logarithm of the number of RTA partners, and a dummy variable which is one if the RTA partners are drawn from more than one WTO region, and zero otherwise. We are also interested in whether the economic characteristics of the members matter substantially. ${ }^{7}$ Accordingly, we include the natural log of the average openness (trade/GDP ratio) of the RTA members, log average income (measured as real GDP per capita), RTA export-importance 
(measured as exports to RTA partners, relative to RTA GDP), and size (measured as log average population). We gather data on national characteristics from the World Bank's World Development Indicators.

\section{Key Results}

Our principal results are presented in Table 2. The column at the extreme left of the table constitutes our baseline default model. It shows the coefficient effects for the four variables that prove to be robust determinants of the length of RTA negotiations.

Negotiations tend to be more protracted for more RTA members at the negotiation table ("Log Number of RTA members"). Since we tabulate our results as coefficients, the negative sign indicates that the length of negotiations rises with the number of countries involved in RTA negotiations. This effect is significant from both the statistical and economic perspectives; trade negotiations are clearly more difficult with more countries sitting at the table. Regional diversity also seems to slow down the process significantly; our dummy variable for RTAs involving members for more than one country also has a large effect on duration. ${ }^{8}$ We consider both of these results intuitive and sensible. Said differently, bilateral agreements between neighbors take less time to be hammered out, an unsurprising result.

We illustrate these key results in Figures 2 and 3, which show a number of different survival functions for the length of RTA negotiations. The graphs are based on our default specification in Table 2, with other control variables held at their average values. Figure 2 shows clearly that bilateral negotiations are much more 
likely to be concluded than multilateral ones. Similarly, Figure 3 makes it clear that negotiations are much more protracted for RTAs that span regions compared with intra-region negotiations.

Our default results in Table 2 also demonstrate slightly weaker results for two other effects of interest to us: openness and income. In particular, we find that RTA partners that are more open to trade and richer tend to conclude their negotiations more quickly.

We have performed two standard specification tests for the Cox model: the link and Schoenfeld-residual tests. Reassuringly, neither test indicates any misspecification.

\section{Sensitivity Analysis}

Our default results are presented at the extreme left of Table 2; the remainder of it provides some sensitivity analysis. Of special interest is the role of intra-RTA exports (measured relative to GDP), which we include as a potential determinant in another column of Table 2. Surprisingly, we estimate a non-result: higher export-toGDP ratios within the RTA do not appear to speed up negotiations. The same is true of the effect of RTA size (measured as population), and intra-RTA income divergence; neither has a measureable effect on the duration of negotiations.

Extra sensitivity analysis is provided in Tables 3 through 5 . In each table, we tabulate our default baseline estimate at the extreme left of the table, and then add additional factors, both one by one and together. Table 3 adds a dummy variable that indicates whether both goods and services are covered by the RTA (rather than 
just goods alone), as well as two measures of the financial depth of the economy. Table 4 focuses on whether the US or the EU/EC play special roles in the length of RTA negotiations; Table 5 focuses on non-linear interactive effects. The bottom line from these sensitivity checks is clear: our results appear to be robust.

\section{Summary and Conclusion}

In this short paper, we have empirically modeled the duration of trade negotiations; that is, the length of time between the start of trade talks and their conclusion. Since the world has experienced only eight rounds of global trade talks through the GATT/WTO mechanism, we use data from 88 regional trade agreements between 1988 and 2009. We estimate a plain-vanilla semi-parametric Cox proportional hazards model and find four intuitive results. Trade negotiations are more protracted when there are more countries at the negotiation table, and when the countries are not from the same region. Negotiations between more open and richer countries are also finished more quickly.

Our results lead us to be pessimistic about the prospects for future global trade talks. The membership of the WTO continues to grow as the few remaining outsider countries (like Russia) join. As the number of participants and the diversity of their preferences grows, it becomes increasingly difficult to imagine a successful conclusion to the Doha round, let alone future liberalization rounds engineered under the auspices of the WTO. While multilateral liberalization has many advantages over regional trade liberalization, feasibility does not appear to be among them. 


\section{References}

Cleves, Mario, Roberto Gutierrez, William Gould and Yulia Marchenko (2004) An Introduction to Survival Analysis Using STATA, College Station: Stata Press.

Cox, D. R. (1972), "Regression Models and Life-tables," Journal of the Royal Statistical Society, Series B, Vol. 34, pp. 187-220.

Moser, Christoph and Andrew K. Rose (2011) "Who Benefits from Regional Trade Agreements? The View from the Stock Market" NBER Working Paper No. 17,415 and CEPR Discussion Paper No. 8566. 


\section{Table 1: Duration of GATT/WTO Rounds}

\begin{tabular}{ccccc}
\hline \hline Round & Initiated & Completed & Participants & Duration \\
\hline Geneva & Apr-1947 & Okt-1947 & 23 & 6 months \\
Annecy & Apr-1949 & Aug-1949 & 13 & 4 months \\
Torquay & Sep-1950 & Apr-1951 & 38 & 7 months \\
Geneva II & Jan-1955 & Mai-1956 & 26 & 16 months \\
Dillon & Sep-1960 & Jul-1962 & 26 & 22 months \\
Kennedy & Mai-1964 & Jun-1967 & 62 & 37 months \\
Tokyo & Sep-1973 & Nov-1979 & 102 & 74 months \\
Uruguay & Sep-1986 & Apr-1994 & 123 & 91 months \\
Doha & Nov-2001 & & 153 & $>123$ months \\
\hline \hline
\end{tabular}

Reference: http://www.wto.org/gatt_docs/English/SULPDF/91030141.pdf

http://www.wto.org/english/thewto_e/whatis_e/tif_e/fact4_e.htm 
Table 2: Baseline - Determinants of Duration of RTA-negotiations

\begin{tabular}{lccccc}
\hline \hline Model & Default & $\begin{array}{c}\text { Exports } \\
\text { within RTA }\end{array}$ & $\begin{array}{c}\text { RTA's } \\
\text { Population }\end{array}$ & $\begin{array}{c}\text { RTA's Income } \\
\text { Divergence }\end{array}$ & Full Model \\
\hline Log Number of RTA partners & $-0.642^{* *}$ & $-0.639^{* *}$ & $-0.650^{* *}$ & $-0.672^{* *}$ & $-0.715^{* *}$ \\
& $(0.13)$ & $(0.14)$ & $(0.15)$ & $(0.14)$ & $(0.17)$ \\
Cross-regional RTA & $-0.687^{* *}$ & $-0.707^{*}$ & $-0.666^{* *}$ & $-0.739^{* *}$ & $-0.714^{*}$ \\
& $(0.22)$ & $(0.28)$ & $(0.25)$ & $(0.24)$ & $(0.28)$ \\
RTA's log Trade/GDP & $0.585^{*}$ & $0.590^{*}$ & $0.598^{*}$ & $0.613^{* *}$ & $0.675^{*}$ \\
& $(0.24)$ & $(0.24)$ & $(0.27)$ & $(0.24)$ & $(0.28)$ \\
RTA's log real GDP p/c & $0.245^{*}$ & $0.246^{*}$ & $0.253^{*}$ & $0.246^{*}$ & $0.276^{*}$ \\
& $(0.12)$ & $(0.12)$ & $(0.13)$ & $(0.12)$ & $(0.13)$ \\
RTA's Exports to RTA partners/GDP & & -0.262 & & -0.310 \\
& & $(1.93)$ & & $(1.97)$ \\
RTA's log Population & & & 0.021 & & 0.075 \\
& & & $(0.11)$ & & $(0.12)$ \\
RTA's IQR of log real GDP p/c & & & & -0.069 & -0.103 \\
& & & & $(0.10)$ & $(0.10)$ \\
\hline Number of Observations & 296 & 296 & 296 & 296 & 296 \\
Log-Likelihood & -297.5 & -297.5 & -297.4 & -297.3 & -297.1 \\
\hline \hline
\end{tabular}

Note: Each column is estimated via a Cox proportional hazards model. Estimates based on 88 RTAs from 1988 to 2009 (see Moser and Rose, 2011, for details on data set). Survival time regressions employ the RTA negotiation duration in days as dependent variable. The results are shown as coefficients, not hazard ratios. Hence, negative coefficients indicate longer negotiations relative to the baseline. Log Number of RTA partners refers to number of signatories of RTA (in logarithm). Dummy variable Cross-regional RTA one for RTAs with members from different regions. The variables RTA's log Trade/GDP, RTA's log real GDP p/c, RTA's Exports to RTA partners/GDP and RTA's log Population refer to the RTA's average. RTA's IQR of log real GDP p/c measures interquartile range of income within RTA. Coefficients significantly different from zero marked at [0.10] 0.05 (0.01) with [one circle] one (two) asterisk(s). 


\section{Table 3: Extra Controls - Determinants of Duration of RTA- negotiations}

\begin{tabular}{lccccc}
\hline \hline Model & Default & $\begin{array}{c}\text { Coverage } \\
\text { of RTA }\end{array}$ & $\begin{array}{c}\text { RTA's } \\
\text { Listed } \\
\text { Firms }\end{array}$ & $\begin{array}{c}\text { RTA's Stock } \\
\text { Market }\end{array}$ & Full Model \\
\hline Log Number of RTA partners & $-0.642^{* *}$ & $-0.605^{* *}$ & $-0.747^{* *}$ & $-0.757^{* *}$ & $-0.717^{* *}$ \\
& $(0.13)$ & $(0.14)$ & $(0.18)$ & $(0.15)$ & $(0.18)$ \\
Cross-regional RTA & $-0.687^{* *}$ & $-0.648^{* *}$ & $-0.802^{* *}$ & $-0.731^{* *}$ & $-0.674^{*}$ \\
& $(0.22)$ & $(0.22)$ & $(0.27)$ & $(0.23)$ & $(0.28)$ \\
RTA's log Trade/GDP & $0.585^{*}$ & $0.537^{*}$ & $0.573^{*}$ & $0.799^{* *}$ & $0.760^{*}$ \\
& $(0.24)$ & $(0.25)$ & $(0.25)$ & $(0.27)$ & $(0.32)$ \\
RTA's log real GDP p/c & $0.245^{*}$ & $0.213^{\circ}$ & $0.259^{*}$ & $0.298^{*}$ & $0.257^{*}$ \\
& $(0.12)$ & $(0.12)$ & $(0.12)$ & $(0.12)$ & $(0.12)$ \\
Goods \& Services included & & 0.217 & & & 0.296 \\
& & $(0.28)$ & & & $(0.28)$ \\
RTA's log number of Listed Firms & & & -0.154 & & 0.005 \\
& & & $(0.18)$ & & $-0.25)$ \\
RTA's log National Stocks/GDP & & & & $(0.14)$ & -0.252 \\
& & & & $0.20)$ \\
\hline Number of Observations & 296 & 296 & 296 & 296 & 296 \\
Log-Likelihood & -297.5 & -297.2 & -297.1 & -296.3 & -295.8 \\
\hline \hline
\end{tabular}

Note: Each column is estimated via a Cox proportional hazards model. Estimates based on 88 RTAs from 1988 to 2009 (see Moser and Rose, 2011, for details on data set). Survival time regressions employ the RTA negotiation duration in days as dependent variable. The results are shown as coefficients, not hazard ratios. Hence, negative coefficients indicate longer negotiations relative to the baseline. Log Number of RTA partners refers to number of signatories of RTA (in logarithm). Dummy variable Cross-regional RTA [Goods \& Services included] one for RTAs with members from different regions [RTAs covering goods and services - and not only goods]. The variables RTA's log Trade/GDP, RTA's log real GDP p/c, RTA's log number of Listed Firms and RTA's log National Stocks/GDP refer to the RTA's average. Coefficients significantly different from zero marked at [0.10] 0.05 (0.01) with [one circle] one (two) asterisk(s). 


\section{Table 4: RTAs, EU and the US - Determinants of Duration of RTA-negotiations}

\begin{tabular}{lccccc}
\hline \hline Model & Default & $\begin{array}{c}\text { RTA } \\
\text { involved }\end{array}$ & $\begin{array}{c}\text { EU I EC } \\
\text { involved }\end{array}$ & $\begin{array}{c}\text { US } \\
\text { involved }\end{array}$ & Full Model \\
\hline Log Number of RTA partners & $-0.642^{* *}$ & $-0.497^{* *}$ & $-0.775^{* *}$ & $-0.608^{* *}$ & -0.504 \\
& $(0.13)$ & $(0.19)$ & $(0.26)$ & $(0.13)$ & $(0.37)$ \\
Cross-regional RTA & $-0.687^{* *}$ & $-0.556^{*}$ & $-0.688^{* *}$ & $-0.675^{* *}$ & $-0.547^{*}$ \\
& $(0.22)$ & $(0.24)$ & $(0.22)$ & $(0.23)$ & $(0.27)$ \\
RTA's log Trade/GDP & $0.585^{*}$ & $0.603^{*}$ & $0.616^{*}$ & $0.704^{*}$ & $0.747^{*}$ \\
& $(0.24)$ & $(0.24)$ & $(0.26)$ & $(0.28)$ & $(0.31)$ \\
RTA's log real GDP p/c & $0.245^{*}$ & $0.246^{*}$ & $0.242^{*}$ & $0.204^{\circ}$ & $0.200^{\circ}$ \\
& $(0.12)$ & $(0.12)$ & $(0.12)$ & $(0.12)$ & $(0.12)$ \\
One Party RTA & & -0.430 & & & -0.413 \\
& & $(0.33)$ & & & $(0.37)$ \\
EU / EC part of RTA & & & 0.388 & & 0.107 \\
& & & $(0.52)$ & & 0.431 \\
US part of RTA & & & & $(0.32)$ & 0.479 \\
& & & & $0.33)$ \\
\hline Number of Observations & 296 & 296 & 296 & 296 & 296 \\
Log-Likelihood & -297.5 & -296.5 & -297.2 & -296.9 & -295.9 \\
\hline \hline
\end{tabular}

Note: Each column is estimated via a Cox proportional hazards model. Estimates based on 88 RTAs from 1988 to 2009 (see Moser and Rose, 2011, for details on data set). Survival time regressions employ the RTA negotiation duration in days as dependent variable. The results are shown as coefficients, not hazard ratios. Hence, negative coefficients indicate longer negotiations relative to the baseline. Log Number of RTA partners refers to number of signatories of RTA (in logarithm). Dummy variables One Party RTA, EU / EC part of RTA and US part of RTA one for RTAs with another RTA, EU / EC or US involved. The variables RTA's log Trade/GDP and RTA's log real GDP p/c refer to the RTA's average. Coefficients significantly different from zero marked at [0.10] 0.05 (0.01) with [one circle] one (two) asterisk(s). 


\section{Table 5: Bilateral RTAs and Non-linearities}

\begin{tabular}{|c|c|c|c|c|c|}
\hline Model & Default & $\begin{array}{c}\text { RTA } \\
\text { involved }\end{array}$ & $\begin{array}{l}\text { EU / EC } \\
\text { involved }\end{array}$ & $\begin{array}{c}\text { US } \\
\text { involved }\end{array}$ & Full Model \\
\hline Log Number of RTA partners & $\begin{array}{c}-0.642^{* *} \\
(0.13)\end{array}$ & $\begin{array}{l}-0.644^{* *} \\
(0.17)\end{array}$ & $\begin{array}{c}-0.531^{\circ} \\
(0.32)\end{array}$ & & \\
\hline Cross-regional RTA & $\begin{array}{c}-0.687^{* *} \\
(0.22)\end{array}$ & $\begin{array}{c}-0.695^{*} \\
(0.35)\end{array}$ & $\begin{array}{c}-0.670^{* *} \\
(0.23)\end{array}$ & $\begin{array}{c}-0.528^{*} \\
(0.23)\end{array}$ & $\begin{array}{c}-0.674^{\circ} \\
(0.39)\end{array}$ \\
\hline RTA's log Trade/GDP & $\begin{array}{l}0.585^{\star} \\
(0.24)\end{array}$ & $\begin{array}{l}0.585^{*} \\
(0.24)\end{array}$ & $\begin{array}{l}0.582^{*} \\
(0.24)\end{array}$ & $\begin{array}{l}0.537^{*} \\
(0.26)\end{array}$ & $\begin{array}{l}0.546^{*} \\
(0.25)\end{array}$ \\
\hline RTA's log real GDP p/c & $\begin{array}{l}0.245^{*} \\
(0.12)\end{array}$ & $\begin{array}{l}0.245^{*} \\
(0.12)\end{array}$ & $\begin{array}{l}0.246^{*} \\
(0.12)\end{array}$ & $\begin{array}{l}0.219^{\circ} \\
(0.11)\end{array}$ & $\begin{array}{l}0.217^{\circ} \\
(0.11)\end{array}$ \\
\hline \multicolumn{2}{|l|}{ Log Number of RTA partners } & $\begin{array}{l}0.005 \\
(0.21)\end{array}$ & & & \\
\hline \multicolumn{2}{|l|}{ Bilateral RTA } & & $\begin{array}{l}0.217 \\
(0.60)\end{array}$ & $\begin{array}{l}1.032^{* *} \\
(0.27)\end{array}$ & $\begin{array}{l}0.840^{*} \\
(0.42)\end{array}$ \\
\hline \multicolumn{2}{|c|}{ Cross-regional RTA*Bilateral RTA } & & & & $\begin{array}{l}0.282 \\
(0.47)\end{array}$ \\
\hline $\begin{array}{l}\text { Number of Observations } \\
\text { Log-Likelihood }\end{array}$ & $\begin{array}{c}296 \\
-297.5 \\
\end{array}$ & $\begin{array}{c}296 \\
-297.5\end{array}$ & $\begin{array}{c}296 \\
-297.4 \\
\end{array}$ & $\begin{array}{c}296 \\
-299.0\end{array}$ & $\begin{array}{c}296 \\
-298.8\end{array}$ \\
\hline
\end{tabular}

Note: Each column is estimated via a Cox proportional hazards model. Estimates based on 88 RTAs from 1988 to 2009 (see Moser and Rose, 2011, for details on data set). Survival time regressions employ the RTA negotiation duration in days as dependent variable. The results are shown as coefficients, not hazard ratios. Hence, negative coefficients indicate longer negotiations relative to the baseline. Log Number of RTA partners refers to number of signatories of RTA (in logarithm). Dummy variable Bilateral RTA is one for a bilateral RTA. Furthermore, interaction terms between cross-regional RTA and Log Number of RTA partners and bilateral are added in column (2) and (5), respectively. The variables RTA's log Trade/GDP and RTA's log real GDP p/c refer to the RTA's average. Coefficients significantly different from zero marked at [0.10] 0.05 (0.01) with [one circle] one (two) asterisk(s). 
Figure 1

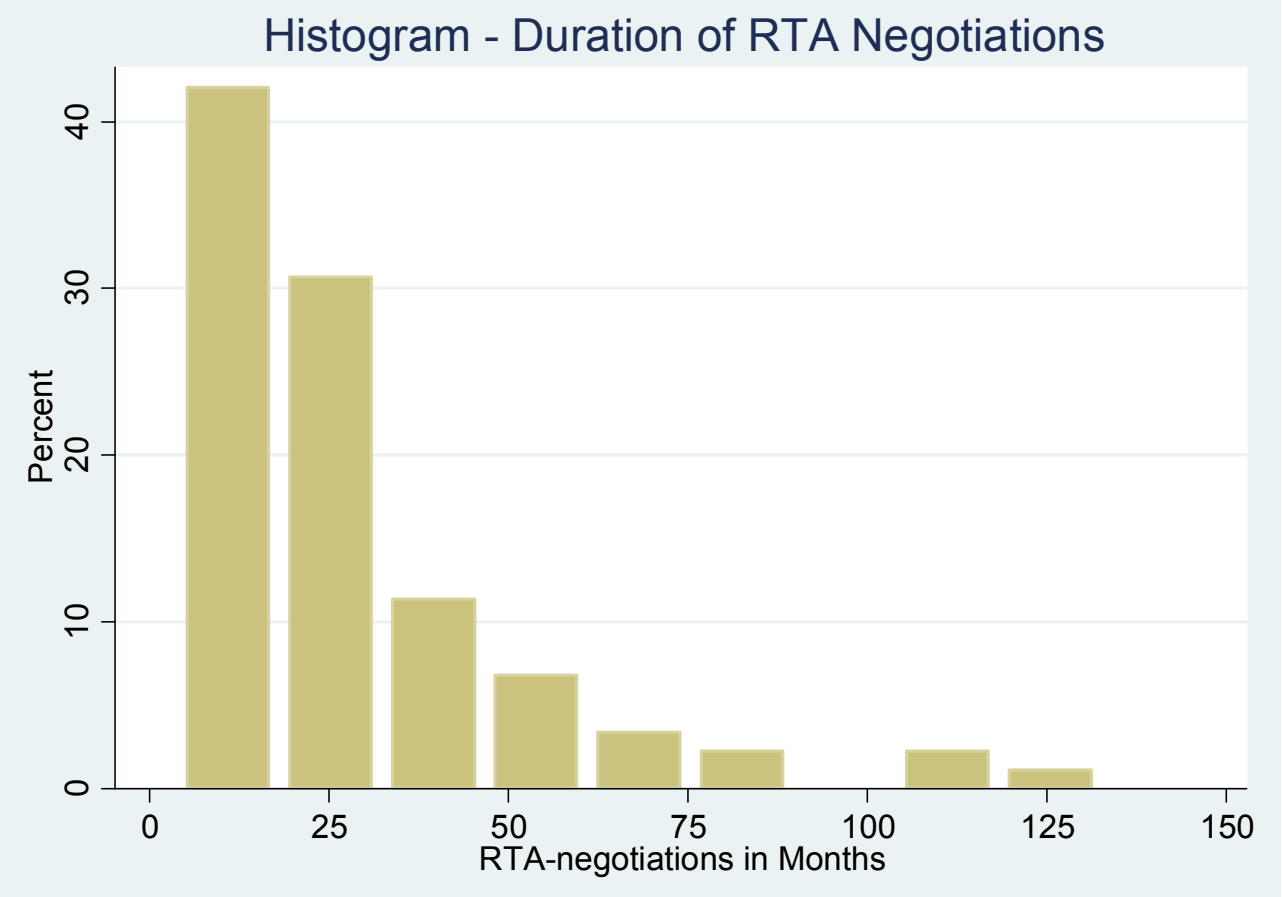




\section{Figure 2}

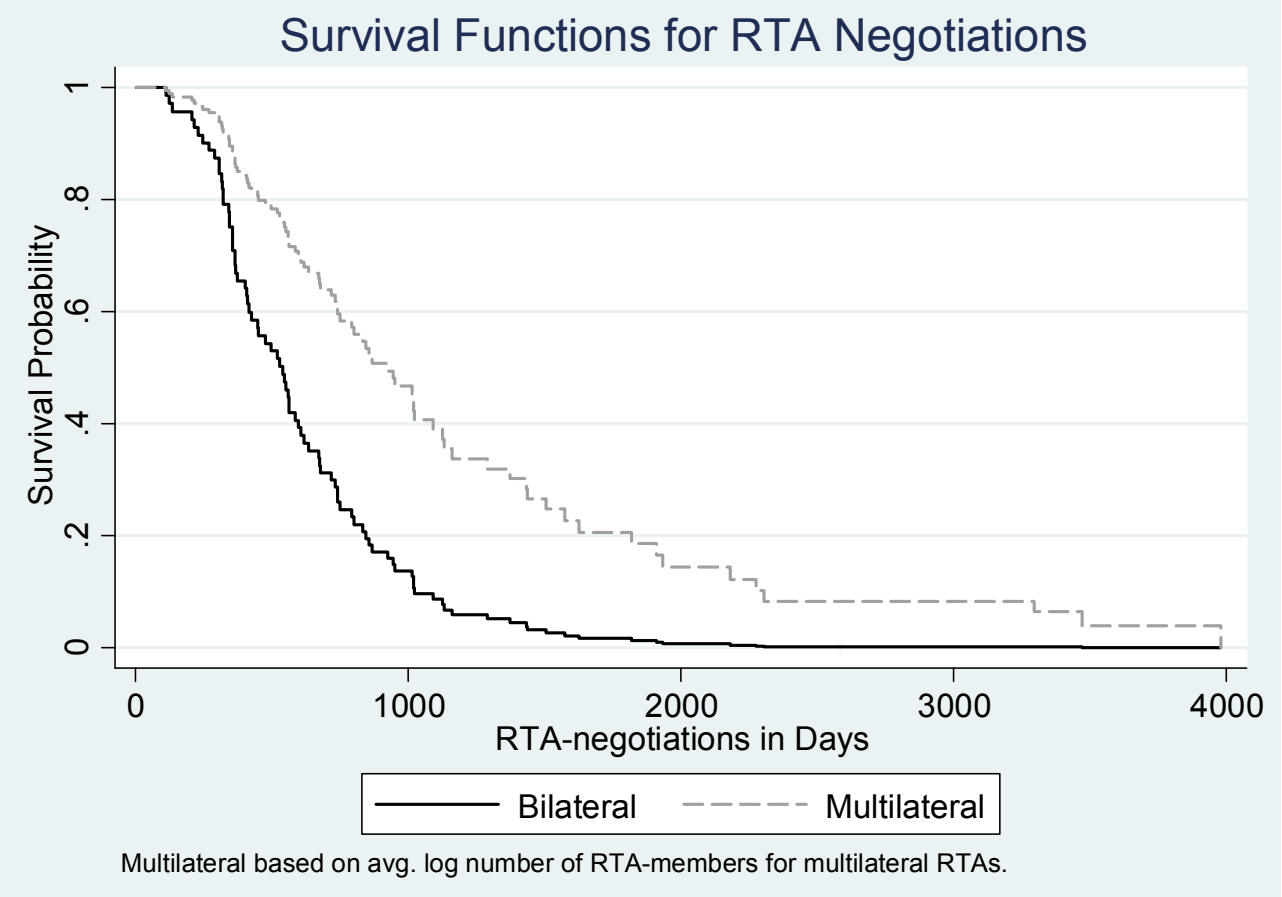




\section{Figure 3}

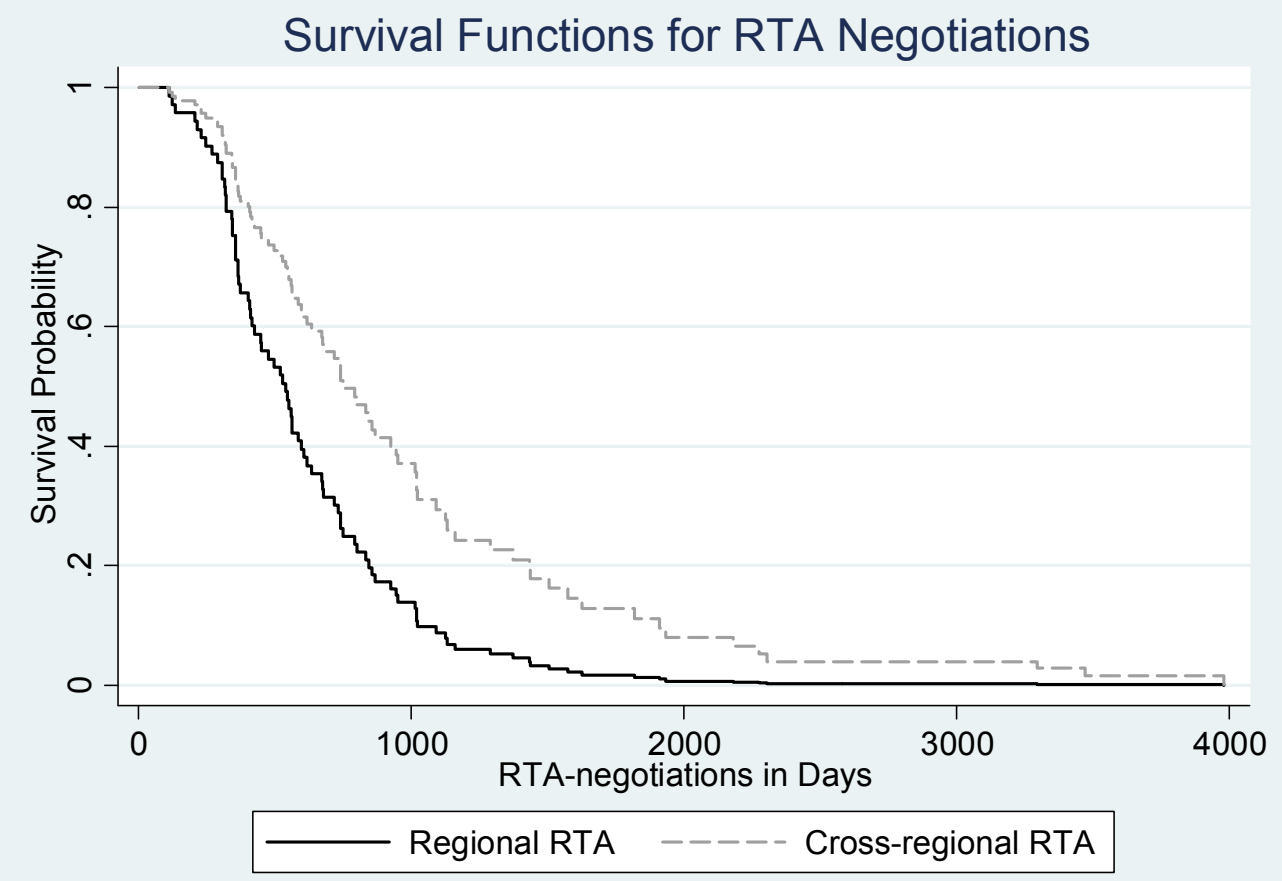




\section{Endnotes}

1 These are listed in the RTA-IS under "List of all RTAs in force" as well as those that have been signed but are not yet in force (listed in the RTA-IS under "List of early announcements").

2 If the countries officially decide to conduct some sort of "pilot study" together, this announcement is defined as the official start of negotiations, so long as de facto negotiations are not conditional on the success of the pilot study.

${ }^{3}$ In the case of entry into the European Community/European Union, we define a "deal" as the European Commission's announcement to officially recommend the accession of a new member. While the European Council technically decides to accept this recommendation, the Council has never yet rejected a positive recommendation.

${ }^{4}$ Note that the samples of this paper and Moser and Rose (2011) diverge because for some RTAs the start date of the negotiations could not be determined by the full-text research.

${ }^{5}$ The full-text research via LexisNexis (LexisNexis Academic) was performed between October and December 2009, at the Haas Business School and between December 2009 and March 2010 at ETH Zurich. The full-text research typically starts with the key-words "free trade" or "trade agreement" and the two respective country names. We restrict ourselves to dates before the respective RTA went into force.

${ }^{6}$ One of the reasons for a gap between the official announcement and the signature ceremony is "legal scrubbing" since it usually takes some time to transform the political will of a general agreement into a contract. (We are not aware of any cases where an agreement has not been followed by the formal signing of a RTA.) A number of RTAs have been signed but not yet ratified; these RTAs are not yet in force (prominent examples would be the US-Korea and US-Colombia RTAs).

${ }^{7}$ Political factors might also play a role in determining the duration of RTA negotiations. We leave this for future research.

${ }^{8}$ The WTO distinguishes between eleven regions, and we use their classification. 